\title{
Root functional change achieves water source separation under vegetation succession
}

Tsutomu Yamanaka

Faculty of Life and Environmental Sciences, University of Tsukuba, Tsukuba 305-8572, Japan tyam@geoenv.tsukuba.ac.jp

Short title: Root functional change achieves water source separation

Keywords: interspecific interaction, root water uptake, water use strategy, niche separation, plant coexistence, stable isotope

\section{Correspondence:}

Tsutomu Yamanaka

Faculty of Life and Environmental Sciences, University of Tsukuba, Tsukuba 305-8572, Japan

$+81-29-853-2538$

$+81-29-853-2530$

tyam@geoenv.tsukuba.ac.jp 


\section{Abstract}

Water source separation can be one of strategies for different plant species to coexist in a community. This study first demonstrates mechanisms of water source separation during vegetation succession. An isotope-incorporated mechanistic model was employed to simulate the xylem water isotopic composition and the root water uptake profile for a Pinus densiflora-Quercus myrsinaefolia mixed stand undergoing secondary succession and a pure $P$. densiflora stand before succession. In the mixed stand, the model successfully simulated the xylem water isotopic composition on the assumption that the root surface resistance per unit length of root $\left(r_{r s}{ }^{*}\right)$ decreases with increasing depth for $P$. densiflora but is constant for $Q$. myrsinaefolia. Uptake fraction for $P$. densiflora was greater in deeper zones but in shallower for Q. myrsinaefolia. In contrast, in the pure stand, a constant $r_{r s}{ }^{*}$ for $P$. densiflora gave good reproducibility in isotope simulation and shallow water uptake dominated. These findings highlight root functional change as a mechanism of water source separation; preexisting $P$. densiflora trees decrease their deep-root $r_{r s}{ }^{*}$ to compensate for an increase in shallow-root $r_{r s}{ }^{*}$. This mechanism was caused by competition against invading $Q$. myrsinaefolia trees. 


\section{INTRODUCTION}

The question of how competing plant species manage to stably coexist is an important topic in community ecology (Silvertown, Dodd, Gowing, \& Mountford, 1999; Silvertown 2004). It has been suggested that competition for limited resources such as water may be reduced by partitioning of resource utilization (Walter, 1971; Tilman, 1982). Although partitioning of root water uptake among different species has been difficult to observe directly, development of an isotopic approach has enabled the characterization of water source separation among different species within a community (Dawson, Mambelli, Plamboeck, Templer, \& Tu, 2002).

In desert scrubland (Ehleringer, Phillips, Schuster, \& Sandquist, 1991), semiarid rangeland (Schwinning, Davis, Richardson, \& Ehleringer, 2002; Darrouzet-Nardi, D’Antonio, \& Dawson, 2006), savanna woodland (Weltzin \& McPherson, 1997) and a Sahelian agroforestry system (Smith, Jarvis, \& Odongo, 1997), woody plants generally tend to take up water from deeper soils than co-occurring herbaceous plants (Walter, 1971). In semiarid woodland, some shrub or low tree species utilize deeper water-sources than co-occurring tall tree species (Flanagan, Ehleringer, \& Marshall, 1992; Williams \& Ehleringer, 2000). In communities under relatively humid climates, the partitioning of water uptake is somewhat irregular. It has been reported that in Mediterranean scrubland (Valentini, Mugnozza, \& Ehleringer, 1992) and temperate savanna (Jackson et al., 1999), most deciduous species tend to use deeper water sources than co-occurring evergreen species. In contrast, in seasonally dry tropical forests, the opposite was found (Jackson, Cavelier, Goldstein, Meinzer, \& Holbrook, 1995) or no significant correlation was observed between the uptake zone and vegetation type (Meinzer et al., 1999). Pinyon pine (Pinus edulis) took up water from shallower zones than co-occurring deciduous oak in semiarid woodlands (Williams \& Ehleringer, 2000), whereas Japanese red pine (Pinus densiflora) utilized deeper water sources than co-occurring evergreen oak in a temperate secondary forest (Yamanaka, Iizuka, \& Tanaka, 2006). The pattern of the water source separation was observed to change in accordance with environmental conditions such as water table depth (Smith, Jarvis, \& Odongo, 1997) or amount of summer rainfall (Williams \& Ehrelinger 2000).

Regardless of the presence or absence of competitors, some plant species rely on shallow water sources, whereas others utilize deep sources, depending on their own rooting strategies to cope with stochastic water availability (Rodriguez-Iturbe, Porporato, Laio, \& Ridolfi, 2001; Collins \& Bras, 2007) and allocation trade-off (Schwinning \& Ehleringer, 2001). One possible interpretation for the water source separation is simply the combination of the intrinsic water-use patterns specific to each species. Another interpretation is that one (or some) of the competing species alter their uptake zone to avoid or lessen interspecific competition for water, thus achieving the water source separation. The mechanisms of water source separation are not currently well understood. If one compares water-use patterns between different stages of vegetation succession, it will be possible to clarify the role or effect of competitors in water source separation.

This study tested a hypothesis that the invasion of competitors alters the water uptake zone of 
preexisting species and examined its mechanisms from the viewpoint of water flow through the soil-plant-atmosphere continuum (SPAC; Philip, 1966). For this purpose, we compared the root water uptake profile (RWUP) between a mixed stand during secondary succession and a pure stand before the succession in a temperate humid climate. In most previous studies using the isotopic approach, water source separation has been qualitatively discussed based on comparison of the isotopic signatures of xylem water between different species (Ehleringer, Phillips, Schuster, \& Sandquist, 1991; Flanagan, Ehleringer, \& Marshall, 1992) or quantitative evaluation using isotope mixing models (e.g., shallow versus deep water sources; Dawson, Mambelli, Plamboeck, Templer, \& $\mathrm{Tu}, 2002$ ). However, Ogle, Wolpert, \& Reynolds (2004) developed a more comprehensive algorithm that reconstructs RWUP with an inverse estimation technique. In the present study, we employed an isotope-incorporated mechanistic model (Yamanaka, Kimura, Sun, Kato, \& Onda, 2017) for reconstructing not only RWUP but also water balance and root zone hydrology.

\section{MATERIALS AND METHODS}

\subsection{Study sites}

The two study stands are located in Tsukuba $\left(36.12^{\circ} \mathrm{N}, 140.09^{\circ} \mathrm{E}, 27 \mathrm{~m}\right.$ a.m.s.1.), central Japan. In this region, Pinus densiflora (Japanese red pine) forest is most common and widespread, although the vegetation climax is Quercus myrsinaefolia (Japanese white oak). The forest has been fragmentated into a number of small stands during urbanization; some of which are still managed and maintained as pure pine stands, and others are unmanaged and are undergoing secondary succession from shade-intolerant pine forest to shade-tolerant oak forest.

The first study site is a pine-oak mixed stand under succession with an area of $17,000 \mathrm{~m}^{2}$. Stand density was 0.068 trees $\mathrm{m}^{-2}$ for $P$. densiflora and 0.218 trees $\mathrm{m}^{-2}$ for $Q$. myrsinaefolia; mean tree height (diameter at breast height; DBH) was $15.0 \mathrm{~m}(18.4 \mathrm{~cm})$ for P. densiflora and $6.7 \mathrm{~m}(4.9 \mathrm{~cm})$ for Q. myrsinaefolia (Iida, Tanaka, \& Sugita, 2005). Understories were composed of Pleioblastus chino, Hosta sieboldiana, and Rhus trichocarpa. According to Iida, Tanaka, \& Sugita (2005), stand density for P. densiflora decreased to some one-fourth of the initial value during 1985-2002. Vertical profiles of root length density could be approximated by exponential curves for both $P$. densiflora and $Q$. myrsinaefolia. Vertical gradient of root length density at shallow zone was steeper for Q. myrsinaefolia than for P. densiflora (Yamanaka et al. 2005; Figure 1).

The second site is a pure pine stand with an area of 2,400 $\mathrm{m}^{2}$, approximately $650 \mathrm{~m}$ north of the mixed stand. In 2005, stand density for $P$. densiflora was 0.03 trees $\mathrm{m}^{-2}$ and mean tree height and DBH were $12 \mathrm{~m}$ and $28 \mathrm{~cm}$, respectively. Understories (mainly P. chino) were cleared several times every year, so they can be expected to have a minimal effect on the rooting or water-uptake strategies of $P$. densiflora. The root density profile was not substantially different from that for $P$. densiflora in the mixed stand.

For both sites, climatic values of annual mean temperature and annual total precipitation are $13.5^{\circ} \mathrm{C}$ and $1159.1 \mathrm{~mm}$, respectively. Monthly precipitation is greater $(120-180 \mathrm{~mm})$ in the warm 
$\left(15-26^{\circ} \mathrm{C}\right)$ period from June to October and smaller $(<50 \mathrm{~mm})$ in the cold $\left(3-6^{\circ} \mathrm{C}\right)$ period from December to February. The vegetation occurs on a loamy, volcanic ash soil (Andosol), 1.8-2.0 m thick, overlying a clay layer. The water table depth usually ranges from 1.3 to $1.5 \mathrm{~m}$ below the ground.

\subsection{Isotopic surveys}

Isotopic survey at the mixed stand was carried out in June to October 2003 and was reported by Yamanaka, Iizuka, \& Tanaka (2006). Stem core or twig samples were taken from three individuals for each of $P$. densiflora and $Q$. myrsinaefolia. Soil water samples were collected from four depths $(10,20,40$, and $80 \mathrm{~cm})$ using suction lysimeters (DIK-8390, DAIKI, Saitama, Japan). The maximum suction level of this equipment is approximately $80 \mathrm{kPa}$, and Iizuka, Yamanaka, \& Tanaka (2004) confirmed that no isotopic fractionation occurred during the soil water extraction. Precipitation samples were also collected every week or month.

Isotopic survey at the pure stand was carried out in June to October 2005. Stem core or twig samples were taken from five $P$. densiflora individuals. Soil water samples were collected from four depths $(10,20,40$, and $80 \mathrm{~cm})$ by the same method as in the mixed stand. Although precipitation samples were not collected, precipitation isotope data measured by Yabusaki \& Tase (2007) are available.

Xylem water was extracted from the stem or twig samples by cryogenic vacuum distillation (Iizuka, Yamanaka, \& Tanaka, 2004). For all water samples, the oxygen isotope ratio $\left({ }^{18} \mathrm{O} /{ }^{16} \mathrm{O}\right)$ was measured by mass spectrometry using a stable isotope ratio mass spectrometer (Finnigan MAT252, Thermo Fisher Scientific Inc., Waltham, MA, USA). The $\mathrm{CO}_{2}$ gas equilibration method (Epstein \& Mayeda, 1953) was used for sample preparation. Measured results are expressed using the $\delta$-notation in parts per thousand (\%), relative to the Vienna Standard Mean Ocean Water (V-SMOW). The accuracy of the isotopic measurement is approximately $\pm 0.1 \%$. From a series of preliminary pot-experiments, we confirmed that the error potentially introduced in the cryogenic vacuum distillation procedure was no more than 0.2\%o (Iizuka, Yamanaka, \& Tanaka, 2004). Because these experiments showed that hydrogen isotope ratio $\left({ }^{2} \mathrm{H} /{ }^{1} \mathrm{H}\right)$ cannot be accurately measured, probably owing to isotopic exchange with organic matter, only $\delta^{18} \mathrm{O}$ data were employed in the present study.

\subsection{Model and data}

We used the isotope-incorporated mechanistic model isoRHEA, developed by Yamanaka, Kimura, Sun, Kato, \& Onda (2017). The original model (Figure 2a) computes energy and water budgets and precipitation interception for a 3-layer canopy (i.e., tree canopy, understory, and ground layers) and then estimates water and isotope transport (including uptake by roots) within a multi-layered soil (see Supplement of Yamanaka, Kimura, Sun, Kato, \& Onda (2017) for full information). Transpiration and evaporation of intercepted water from the tree canopy and the understory, and evaporation from the forest floor soil are computed separately. This model was applied to the pure stand, but negligibly small leaf area index (LAI; 0.001) was assigned for the understory layer because of mowing.

For the mixed stand, the model was modified to allow consideration of the below-ground 
competition between $P$. densiflora and $Q$. myrsinaefolia (Figure 2b). In this case, the tree canopy layer corresponds to $P$. densiflora, the understory layer corresponds to $Q$. myrsinaefolia, and the ground layer corresponds to both undergrowth vegetation and the soil. However, the $P$. densiflora canopy does not always overlap that of $Q$. myrsinaefolia because stand density is not very high. Therefore, radiation fluxes were divided horizontally into two tree layers (i.e., $P$. densiflora and $Q$. myrsinaefolia) by considering fractional LAI, and the interaction between the ground layer and each of the two tree-layers was computed as follows:

$$
\begin{aligned}
& S_{P}^{*}=\frac{L A I_{P}}{L A I_{P}+L A I_{Q}}\left[f_{P}-\alpha_{P}+f_{P}\left(1-f_{P}\right) \alpha_{G}\right] S, \\
& S_{Q}^{*}=\frac{L A I_{Q}}{L A I_{P}+L A I_{Q}}\left[f_{Q}-\alpha_{Q}+f_{Q}\left(1-f_{Q}\right) \alpha_{G}\right] S, \\
& S_{G}^{*}=\frac{L A I_{P}\left(1-f_{C}\right)+L A I_{Q}\left(1-f_{U}\right)}{L A I_{P}+L A I_{Q}}\left(1-\alpha_{G}\right) S, \\
& L_{P}^{*}=\frac{L A I_{P}}{L A I_{P}+L A I_{Q}} f_{P}\left[L+\sigma T_{G}{ }^{4}-2 \sigma T_{P}{ }^{4}\right], \\
& L_{Q}^{*}=\frac{L A I_{Q}}{L A I_{P}+L A I_{Q}} f_{Q}\left[L+\sigma T_{G}{ }^{4}-2 \sigma T_{Q}{ }^{4}\right], \\
& L_{G}^{*}=\frac{\left[L A I_{P}\left(1-f_{Q}\right)+L A I_{Q}\left(1-f_{P}\right)\right] L+L A I_{P} f_{P} \sigma T_{P}{ }^{4}+L A I_{Q} f_{Q} \sigma T_{Q}{ }^{4}}{L A I_{P}+L A I_{Q}}-\sigma T_{G}{ }^{4},
\end{aligned}
$$

where $\left.S^{*}(\mathrm{~W} \mathrm{~m})^{-2}\right)$ is the net absorbed short-wave radiation, $L A I\left(\mathrm{~m}^{2} \mathrm{~m}^{-2}\right)$ is the LAI, $f$ the fractional interception of radiation fluxes, $\alpha$ is the albedo, $S\left(\mathrm{~W} \mathrm{~m}^{-2}\right)$ is the downward short-wave radiation above the canopy, $L^{*}\left(\mathrm{~W} \mathrm{~m}^{-2}\right)$ is the net absorbed long-wave radiation, $L\left(\mathrm{~W} \mathrm{~m}^{-2}\right)$ is the downward long-wave radiation above the canopy, $\sigma\left(\mathrm{W} \mathrm{m}^{-2} \mathrm{~K}^{-4}\right)$ is the Stefan-Boltzmann constant, $T(\mathrm{~K})$ is the temperature, and subscripts $P, Q$, and $G$ denote the $P$. densiflora tree layer, the $Q$. myrsinaefolia tree layer, and the ground layer, respectively.

In addition to the above modification, no isotopic fractionation due to forest floor evaporation was assumed for the mixed stand because the ground surface in the stand was densely covered by undergrowth. In contrast, in the pure stand, Q. myrsinaefolia and undergrowth were not apparent. Therefore, we considered isotopic fractionation due to soil evaporation on the basis of the Craig-Gordon model (Craig \& Gordon, 1965; Yamanaka, Kimura, Sun, Kato, \& Onda, 2017). 
As input to the model, we used meteorological data from the Japan Meteorological Agency for Tsukuba (station ID = 40336; air temperature, relative humidity, precipitation, wind speed, air pressure, and sunshine duration; $7 \mathrm{~km}$ south from the study sites). Downward shortwave and longwave radiation fluxes above the canopy were estimated using these observed values by the method of Allen, Pereira, Raes, \& Smith (1998).

Analogous to Ohm's law, the root water uptake by trees for each species is given as:

$$
\begin{aligned}
& U_{r}=\frac{\psi_{r c}-\psi}{r_{t o t}}=\frac{\psi_{r c}-\psi}{r_{s m}+r_{r s}+r_{r x}}, \\
& \psi_{r c}=\frac{\left(\sum_{i=1}^{n} \frac{\psi}{r_{t o t}}\right)-T_{r}}{\sum_{i=1}^{n} \frac{1}{r_{t o t}}},
\end{aligned}
$$

where $U_{r}\left(\mathrm{~kg} \mathrm{~m}^{-2} \mathrm{~s}^{-1}\right)$ is the root water uptake from each soil layer for each species, $\psi_{r c}\left(\mathrm{~J} \mathrm{~kg}^{-1}\right)$ is the plant water potential at the root crown, $\psi\left(\mathrm{J} \mathrm{kg}^{-1}\right)$ is the water potential in a soil layer, $r_{t o t}\left(\mathrm{~m}^{4} \mathrm{~s}^{-1}\right.$ $\left.\mathrm{kg}^{-1}\right)$ is the total resistance, $r_{s m}\left(\mathrm{~m}^{4} \mathrm{~s}^{-1} \mathrm{~kg}^{-1}\right)$ is the soil matrix resistance, $r_{r s}\left(\mathrm{~m}^{4} \mathrm{~s}^{-1} \mathrm{~kg}^{-1}\right)$ is the root surface resistance, $r_{r x}\left(\mathrm{~m}^{4} \mathrm{~s}^{-1} \mathrm{~kg}^{-1}\right)$ is the root xylem resistance, $i$ is the layer number, and $n$ is the total number of the soil layers, and $T_{r}\left(\mathrm{~kg} \mathrm{~m}^{-2} \mathrm{~s}^{-1}\right)$ is the transpiration rate for each species. The three resistances can be given as (modified from Yamanaka, Kimura, Sun, Kato, \& Onda, 2017):

$$
\begin{aligned}
& r_{s m}=\frac{1}{4 \pi K_{\psi} L_{r} \Delta_{z}}, \\
& r_{r s}=\frac{\theta_{s a t} r_{r s}^{*}}{\theta L_{r} \Delta_{z}}, \\
& r_{r x}=\frac{r_{r x}^{*} z}{\tau_{r} L_{r}},
\end{aligned}
$$

where $K_{\psi}\left(\mathrm{kg} \mathrm{s} \mathrm{m}^{-3}\right)$ is the unsaturated hydraulic conductivity, $L_{r}\left(\mathrm{~m} \mathrm{~m}^{-3}\right)$ is the root length density, $\Delta_{z}(\mathrm{~m})$ is the thickness of each soil layer, $\theta_{s a t}\left(\mathrm{~m}^{3} \mathrm{~m}^{-3}\right)$ is the saturated soil water content, $r_{r s}{ }^{*}\left(\mathrm{~m}^{3} \mathrm{~s}^{-1}\right.$ $\left.\mathrm{kg}^{-1}\right)$ is the root surface resistance per unit length of root, $\theta\left(\mathrm{m}^{3} \mathrm{~m}^{-3}\right)$ is the soil water content, $r_{r x}{ }^{*}(\mathrm{~m}$ $\mathrm{s}^{-1} \mathrm{~kg}^{-1}$ ) is the root xylem resistance per unit length of root, $z(\mathrm{~m})$ is the depth, and $\tau_{r}$ is the root tortuosity parameter. Consequently, RWUP is determined by the difference in water potential and resistance to the water flow within the root-soil system like a parallel circuit, as schematically illustrated in Figure 2. An output of xylem water isotope ratio is expected to be sensitive to the reconstructed RWUP, and thus comparison between modelled and observed values helps to validate the model.

LAI and soil parameters used in the model are summarized in Table 1. The other parameter values 
were the same as those described in Yamanaka, Kimura, Sun, Kato, \& Onda (2017) except for the below. The $r_{r s}{ }^{*}$ was assumed to be constant in the original isoRHEA. In this study, however, it was given as a constant or an exponential function of the depth as follows:

$$
r_{r s}^{*}=a \exp (b z)
$$

where $a$ and $b$ are experimental constants. Although a large number of experimental cases have been attempted, we show below the results of two cases (Case A and Case B) for each of the two stands, as described in Table 2. The value of $b$ was selected considering reproducibility of xylem water isotope ratio because it is sensitive to $b$. The value of $a$ has little effect on xylem water isotope ratio and RWUP, although $\psi_{r c}$ depends on $a$. Kobayashi (1999) reported that $\psi_{r c}$ of $P$. densiflora at the mixed stand was from -5000 to $-7000 \mathrm{kPa}$ at the lowest in summer. Therefore, we selected the value of $a$ to cause the minimum water potential to lie within such a range.

\section{RESULTS AND DISCUSSION}

\subsection{Isotopic variability and RWUP at the mixed stand}

Observed soil water $\delta^{18} \mathrm{O}$ at shallow $(<10-20 \mathrm{~cm}$ depth) zones drastically decreased in mid-August in response to a large storm event associated with low $\delta^{18} \mathrm{O}$ in precipitation, and then recovered gradually (Figure 3). Temporal variation pattern of observed xylem water $\delta^{18} \mathrm{O}$ of $Q$. myrsinaefolia was similar to that of shallow soil water $\delta^{18} \mathrm{O}$, whereas xylem water $\delta^{18} \mathrm{O}$ of $P$. densiflora was close to soil water $\delta^{18} \mathrm{O}$ at $80-\mathrm{cm}$ depth.

Assuming constant $r_{r s}{ }^{*}$ (Case A), the mechanistic model successfully reproduced xylem water $\delta^{18} \mathrm{O}$ of $Q$. myrsinaefolia but failed for $P$. densiflora (Figure 3a). When we assumed that $r_{r s}{ }^{*}$ for $P$. densiflora decreases with increasing depth (Case B), the reproducibility of xylem water $\delta^{18} \mathrm{O}$ remarkably improved; in this case, $P$. densiflora trees took up more water from deeper zones (Figure $3 b)$.

In both cases, temporal variations of reproduced soil water $\delta^{18} \mathrm{O}$ at four depths generally agreed with observation. Although the amplitude and phase of those variations were different between the model and observations, such deviations are attributable to horizontal heterogeneity in precipitation and soil water fluxes. Minor deviations in the estimated xylem water $\delta^{18} \mathrm{O}$ from the observations was related to both horizontal heterogeneity of observed soil water $\delta^{18} \mathrm{O}$ and incompleteness of reproduced soil water $\delta^{18} \mathrm{O}$.

Consequently, it is most likely that $Q$. myrsinaefolia trees rely mainly on shallow soil water, whereas $P$. densiflora trees utilize more water from deeper zones. This result is consistent with the estimation by Yamanaka, Iizuka, \& Tanaka (2006) from isotopic data alone. However, uptake zone for $P$. densiflora was suggested to be broader in the present study than they expected.

\subsection{Isotopic variability and RWUP at the pure stand}

Observed soil water $\delta^{18} \mathrm{O}$ and its temporal variation range were greater in shallow zones than in deep 
zones (Figure 4). Observed xylem water $\delta^{18} \mathrm{O}$ of $P$. densiflora was similar to soil water $\delta^{18} \mathrm{O}$ at the intermediate (20-40-cm depth) zone.

In contrast to the mixed stand, Case A was a good approximation for reproducing xylem water $\delta^{18} \mathrm{O}$ of $P$. densiflora, and the uptake fraction was greater in shallower zones (Figure 4a). In contrast, in Case B, xylem water $\delta^{18} \mathrm{O}$ was greatly overestimated (Figure $4 \mathrm{~b}$ ).

The reproducibility of soil water $\delta^{18} \mathrm{O}$ in shallow zones was not substantially different between the two cases. However, $\delta^{18} \mathrm{O}$ at $40-\mathrm{cm}$ and $80-\mathrm{cm}$ depths were considerably underestimated in Case B. This was due to strong the deep-water uptake, which enhanced the downward propagation of isotopic signals more than in reality.

Thus, it is a reasonable interpretation that $P$. densiflora trees in the pure stand utilize more water from shallow zones. This must be an intrinsic water-use-pattern for $P$. densiflora without competitors. In addition, it is likely that $P$. densiflora trees in the mixed stand altered their water source in response to invasion of competitors. As noted in Section 2.1, stand density of $Q$. myrsinaefolia trees was three times greater than that of $P$. densiflora trees. It is likely that invasion of $Q$. myrsinaefolia trees have increased competition for water.

It should be noted that stand density of $P$. densiflora trees was lower in the pure stand than in the mixed stand. One may expect that intraspecific competition can alter the RWUP of $P$. densiflora trees. However, xylem water $\delta^{18} \mathrm{O}$ of all sample trees of $P$. densiflora in the pure stand indicated shallow water use, regardless of the fact that local tree density (or tree spacing) for some sample trees was similar to that in the mixed stand. Therefore, it is likely that alteration of RWUP was induced by interspecific competition rather than intraspecific competition.

\subsection{Validity of water flux estimations and reproduced RWUP}

The performance of water flux estimation by the isoRHEA model has been validated for a Chamaecyparis obtusa stand (Yamanaka, Kimura, Sun, Kato, \& Onda, 2017), whereas it was not validated for the other stands. Uncertainties in assigned parameter values (e.g., stomatal resistance) may introduce errors to the flux estimation. However, model outputs of annual water balance in this study were nearly the same as those previously reported for the same study stands (Table 3). However, there are some minor biases (e.g., overestimation of transpiration from P. densiflora in the pure stand, and underestimation of forest floor evaporation in both stands), which are likely to be caused in part by interannual variation of precipitation conditions.

It should be noted that, in the current version of the isoRHEA model, the dependence of leaf stomatal resistance on soil water conditions is not assumed; thus, the rate of transpiration from $P$. densiflora trees is independent of the $r_{r s}{ }^{*}$ profiles (i.e., Cases A or B) and cannot be related to the reproduced RWUP. This assumption may be inappropriate in some drought cases. In terms of transpiration suppression, the soil moisture deficit can be evaluated by the relative extractable water (REW) defined as follows (Iida, Tanaka, \& Sugita, 2006): 


$$
\mathrm{REW}=\frac{\theta-\theta_{W P}}{\theta_{F C}-\theta_{W P}}
$$

where $\theta$ is the volumetric water content, and subscripts WP and FC indicate wilting point ( $\psi=$ $-1553.2 \mathrm{kPa}=\mathrm{pF} 4.2)$ and field capacity $(\psi=-6.18 \mathrm{kPa}=\mathrm{pF} 1.8)$, respectively. According to Iida, Tanaka, \& Sugita (2006), transpiration suppression due to the soil moisture deficit in the mixed stand does not occur when REW $>0.4$. Sugita (1987) also reported that this fact holds true for the pure stand when REW $>0.6$. In the present study, REW exceeded 0.7 for both stands. Therefore, the above assumption cannot introduce serious errors in reproduced RWUP.

\subsection{Root surface resistance as a key for water source separation}

Judging from isotopic reproducibility, it was found that $r_{r s}{ }^{*}$ was constant for $P$. densiflora in the pure stand and $Q$. myrsinaefolia in the mixed stand. In these cases, shallower water uptake was more dominant (reflecting root density profile). In contrast, only for P. densiflora in the mixed stand, $r_{r s}{ }^{*}$ decreased with increasing depth, and RWUP was relatively flat but with more uptake from deeper zones.

Unfortunately, there are no available data on the measured $r_{r s}{ }^{*}$ values for tree species. Bristow, Campbell, \& Calissendorf (1984) reported that the $r_{r s}{ }^{*}$ value for sunflower was $2.5 \times 10^{10} \mathrm{~m}^{3} \mathrm{~kg}^{-1} \mathrm{~s}^{-1}$. The $r_{r s}{ }^{*}$ values for $P$. densiflora and $Q$. myrsinaefolia estimated in the present study are comparable to the value for sunflower.

Shallow-root $r_{r s}{ }^{*}$ of $P$. densiflora was greater in the mixed stand Case B than in the pure stand Case A (Figure 5). The lowering of metabolic activity of roots is known to have a potential to increase $r_{r s}{ }^{*}$ (Hillel, 1980). Interspecific competition for water (and nutrients) may negatively impact the metabolic activity of the shallow roots. Kume et al. (2003) reported that leaves of $P$. densiflora in western Japan suffer negative physiological effects (i.e., reduction of net photosynthesis, stomatal conductance, and nitrogen content in leaves) from co-occurring understory species through the competition for water and nutrients. Griscom \& Ashton (2003) showed that root competition for water in the presence of bamboo tends to reduce tree growth and/or survival in a bamboo-dominated forest. These findings suggest that competition for water can alter $r_{r s}{ }^{*}$ through change in metabolic activity of the shallow roots of $P$. densiflora.

As opposed to that of shallow roots, the deep-root $r_{r s}{ }^{*}$ of $P$. densiflora was smaller in the mixed stand than in the pure stand. This may be a compensation (Rubio \& Lynch, 2007) for the increase in shallow root resistance during competition. For instance, an increase in the number of root hairs can reduce deep-root $r_{r s}{ }^{*}$.

Change in root resistance of $P$. densiflora enables a reduction of its competition for shallow soil water with $Q$. myrsinaefolia. Indeed, in the mixed stand, minimum soil water potential at the top layer was $1.3 \mathrm{kPa}$ higher in Case B than in Case A. Although the difference in soil water potential is small, it can be enlarged in severe drought periods. Thus, the water source separation in the mixed stand is likely to be an adaptation strategy for P. densiflora. 


\subsection{Implications from the viewpoint of vegetation succession}

Even though the water source separation is an adaptation strategy to cope with invasion of competitors, it is debatable whether it assures stable coexistence. As noted in Section 2.1, stand density for P. densiflora in the mixed stand decreased to one-fourth of initial state during 1985-2002. This is because $P$. densiflora is a shade-intolerant tree species and its seedlings cannot grow under low light conditions (Yamashita \& Hayashi, 1987). Therefore, although water source separation can be an important strategy at a transient state in vegetation succession, it is not always effective for stable coexistence over generations. However, water source separation may support stable coexistence unless there is competition for the other resources.

A remaining debatable issue is why $P$. densiflora trees rather than $Q$. myrsinaefolia trees changed their root resistance. The $Q$. myrsinaefolia trees are younger than $P$. densiflora trees and their transpiration rates were nearly double those of $P$. densiflora. These facts indicate higher assimilation and metabolism, and thus higher competitive power of $Q$. myrsinaefolia. In such cases, shallow roots of $Q$. myrsinaefolia suffered few negative impacts and would not have to reduce their root resistance in deep zones. According to relative strength of competitors, different patterns of water source separation may be achieved.

\section{CONCLUSIONS}

Intrinsically $P$. densiflora trees under humid temperate climate utilize shallow water sources. However, during progression of secondary succession, they came to use a deeper water source as a part of their adaptation strategy to cope with invasion of $Q$. myrsinaefolia trees. Increase of competition for water negatively impacted on the metabolic activity of the shallow roots of $P$. densiflora trees and increased their root surface resistance. To compensate for this, root surface resistance of their deep roots was decreased, probably by increase in the number of root hairs.

In conclusion, interspecies competition under vegetation succession alters the water uptake profile of weak competitors through a change in root surface resistance, and thus water source separation is achieved. This mechanism could be key to improving our understanding of the diverse patterns of differential water uptake. Future research involving direct observation of root resistance and the relationship between stomatal resistance and RWUP are valuable for further validation of simulation results and mechanisms of root resistance change.

\section{ACKNOWLEDGMENTS}

I would like to thank Daigo Matsuo for his help in conducting field survey at the pure stand and Shin'ichi Iida for his helpful information on the mixed stand. I thank Alex Boon of Edanz Group (www.edanzediting.com/ac) for editing a draft of this manuscript, and associate editor and reviewers for their valuable comments to the earlier version of the manuscript. This research was partly supported by a Grant-in-Aid for Scientific Research (No. 23540508 \& 15H02957). 


\section{REFERENCES}

Allen, R. G, Pereira, L. S., Raes, D., \& Smith, M. (1998). Crop evapotranspiration: guidelines for computing crop requirements (FAO Irrigation and Drainage Paper No. 56). Rome: FAO.

Bristow, K. L., Campbell, G. S., \& Calissendorf, C. (1984). The effects of texture on the resistance to water movement within the rhizosphere. Soil Sci. Soc. Am. J., 48, 266-270.

Collins, D. B. G., \& Bras, E. L. (2007). Plant rooting strategies in water-limited ecosystems. Water Resour. Res., 43, W06407. doi:10.1029/2006WR005541

Craig, H., \& Gordon, L. I. (1965). Deuterium and oxygen-18 variations in the ocean and the marine atmosphere. In Tongiorgi E (Ed.), Stable Isotopes of Oceanographic Studies and Paleotemperatures (pp. 9-130). Pisa: Laboratorio di Geologia Nucleare.

Dawson, T. E., Mambelli, S., Plamboeck, A. H., Templer, P. H. \& Tu, K. P. (2002). Stable isotopes in plant ecology. Ann. Rev. Ecol. Sys., 33, 507-559.

Darrouzet-Nardi, A., D’Antonio, C. M., \& Dawson, T. E. (2006). Depth of water acquisition by invading shrubs and resident herbs in a Sierra Nevada meadow. Plant and Soil, 285, 31-43.

Ehleringer, J. R., Phillips, S. L., Schuster, W. S. F., \& Sandquist, D. R. (1991). Differential utilization of summer rains by desert plants. Oecologia, $88,430-434$.

Epstein, S., \& Mayeda, T. (1953). Variation of ${ }^{18} \mathrm{O}$ content of waters from natural sources. Geochim. Cosmochim. Acta, 4, 213-224.

Flanagan, L. B., Ehleringer J. R., \& Marshall, J. D. (1992). Differential uptake of summer precipitation among co-occurring trees and shrubs in a pinyon-juniper woodland. Plant Cell Env., 15, 831-836.

Griscom, B. W., \& Ashton, P. M. S. (2003). Bamboo control of forest succession: Guadua sarcocarpa in Southern Peru. For. Ecol. Manage., 175, 445-454.

Hillel D. (1980). Applications of Soil Physics. San Diego: Academic Press.

Iida, S., Tanaka, T., \& Sugita, M. (2005). Change of interception process due to succession from Japanese red pine to evergreen oak. J. Hydrol., 315, 154-166.

Iida, S., Tanaka, T., \& Sugita, M. (2006). Change of evapotranspiration components due to succession from Japanese red pine to evergreen oak. J. Hydrol., 326, 166-180.

Iizuka, S., Yamanaka, T., \& Tanaka, T. (2004). Extraction of water from a plant for isotopic measurement: pot experiments. Bull. Terrestrial Environ. Res. Center, Univ. Tsukuba, 5, 81-86. (in Japanese)

Jackson, P. C., Cavelier, J., Goldstein, G., Meinzer, F. C., \& Holbrook, N. M. (1995). Partitioning of water resources among plants of a lowland tropical forest. Oecologia, 101, 197-203.

Jackson, P. C., Meinzer, F. C., Bustamante, M., Goldstein, G., Franco, A., Rundel, P. W., Caldas, L., Igler, E. \& Causin, F. (1999). Partitioning of soil water among trees in a Brazilian cerrado ecosystem. Tree Physiol., 19, 717-724.

Kobayashi, Y. (1999). Study on water flow in a soil-plant-atmosphere continuum considering water storage in a stem. (Unpublished doctoral dissertation). University of Tsukuba, Tsukuba. 
Kume, A., Satomura, T., Tsuboi, N., Chiwa, M., Handa, Y.T., Nakane, K., Horikoshi, T., \& Sakugawa, H. (2003). Effects of understory vegetation on the ecophysiological characteristics of an overstory pine, Pinus densiflora. For. Ecol. Manage., 176, 195-203.

Meinzer, F. C., Andrade, J. L., Goldstein, G., Holbrook, N. M., Cavelier, J., \& Wright, S. J. (1999). Partitioning of soil water among canopy trees in a seasonally dry tropical forest. Oecologia, 121, 293-301.

Ogle, K., Wolpert, R. L., \& Reynolds, J.F. (2004). Reconstructing plant root area and water uptake profiles. Ecology, 85, 1967-1978.

Philip, J.R. (1966). Plant water relations: some physical aspects. Ann. Rev. Plant Physiol., 17, 245-268.

Rodriguez-Iturbe, I., Porporato, A., Laio, F., \& Ridolfi, L. (2001). Intensive or extensive use of soil moisture: plant strategies to cope with stochastic water availability. Geophys. Res. Lett., 28, 4495-4497.

Rubio, G. R., \& Lynch, J. P. (2007). Compensation among root classes in Phaseolus vulgaris L. Plant Soil, 290, 307-321.

Schwinning, S., \& Ehleringer, J. R. (2001). Water use trade-offs and optimal adaptations to pulse-driven arid ecosystems. J. Ecol., 89, 464-480.

Schwinning S., Davis, K., Richardson, L., \& Ehleringer, J. R. (2002). Deuterium enriched irrigation indicates different forms of rain use in shrub/grass species of the Colorado Plateau. Oecologia, $130,345-355$.

Silvertown, J., Dodd, M. E., Gowing, D. J. G., \& Mountford, J. O. (1999). Hydrologically defined niches reveal a basis for species richness in plant communities. Nature, 400, 61-63.

Silvertown, J. (2004). Plant coexistence and the niche. Trends Ecol. Evol., 19, 605-611.

Smith, D. M., Jarvis, P. G., \& Odongo, J. C. W. (1997). Sources of water used by trees and millet in Sahelian windbreak systems. J. Hydrol., 198, 140-153.

Sugita, M. (1987). Evaporation from a pine forest (Environ. Res. Center Papers No. 10). Tsukuba: University of Tsukuba.

Tilman, D. (1982). Resource Competition and Community Structure. Princeton: Princeton University Press.

Valentini, R., Mugnozza, G. E. S., \& Ehleringer, J. R. (1992). Hydrogen and carbon isotope ratios of selected species of a mediterranean macchia ecosystem. Functional Ecology, 6, 627-631.

Walter, H. (1971). Ecology of Tropical and Subtropical Vegetation. Edinburgh: Oliver and Boyd.

Weltzin, J. F., \& McPherson, G. R. (1997). Spatial and temporal soil moisture resource partitioning by trees and grasses in a temperate savanna, Arizona, USA. Oecologia, 112, 156-164.

Williams, D. G., \& Ehleringer, J. R. (2000). Intra- and interspecific variation for summer precipitation use in pinyon-juniper woodlands. Ecol. Monog., 70, 517-537.

Yabusaki, S., \& Tase, N. (2007). Formation process of vertical profile of stable isotopes in soil water at TERC. Bulletin of the Terrestrial Environment Research Center the University of Tsukuba, 8, 
17-26. (in Japanese)

Yamanaka, T., Iizuka, S., \& Tanaka, T. (2006). Water source separation among co-occurring plants: an isotope-ecohydrological approach. J. Jpn. Soc. Hydrol. Water Resour., 19, 458-464. (in Japanse)

Yamanaka, T., Kimura, T., Sun, X., Kato, H., and Onda, Y. (2017) : Comparing root water uptake profile estimations from an isotope-calibrated mechanistic model and a mixing model. Hydrological Research Letters, 11, 161-167.

Yamanaka, T., Matsuo, D., Yano, M., Kakubari, J., Iida, S., Wakui, H., Shimizu, R., \& Tanaka, T. (2005). Difference in root system among co-occurring plants in a secondary pine forest undergoing succession, Bull. Terrestrial Environ. Res. Center, Univ. Tsukuba, 6, 39-44. (in Japanese)

Yamashita, T., \& Hayashi, I. (1987). An analytical study on the successional process from Pinus densiflora to Quercus myrsinaefolia stands in Tsukuba, Ibaraki Prefecture. Bull. Tsukuba Univ. Forests, 3, 59-82. (in Japanese) 
Table 1 Leaf area index (LAI) and soil parameters in isoRHEA model

\begin{tabular}{lccc}
\hline \multicolumn{1}{c}{ Parameter } & Unit & \multicolumn{2}{c}{ Value } \\
\cline { 3 - 5 } & & Mixed stand & Pure stand \\
\hline LAI for $P$. densiflora & $\mathrm{m}^{2} \mathrm{~m}^{-2}$ & $1.5^{*}$ & $2.85^{*}$ \\
LAI for $Q$. myrsinaefolia & $\mathrm{m}^{2} \mathrm{~m}^{-2}$ & $1.6^{*}$ & $\mathrm{~N} / \mathrm{A}$ \\
Saturated soil water content & $\mathrm{m}^{3} \mathrm{~m}^{-3}$ & \multicolumn{2}{c}{$0.756^{\dagger}$} \\
Saturated hydraulic conductivity & $\mathrm{kg} \mathrm{s} \mathrm{m}^{-3}$ & \multicolumn{2}{c}{$2.29 \times 10^{-4 \dagger}$} \\
Air entry potential & $\mathrm{J} \mathrm{kg-1}$ & \multicolumn{2}{c}{$-2.65^{\dagger}$} \\
$b$ value for moisture retention curve & - & \multicolumn{2}{c}{$16.704^{\dagger}$} \\
\hline
\end{tabular}

* Modified from Iida, Tanaka, \& Sugita (2005) considering seasonal variation and Iida (personal communication, Oct. 3, 2017)

${ }^{\dagger}$ Measured 
Table 2 Root surface resistance per unit length of root $\left(r_{r s}{ }^{*}, \mathrm{~m}^{3} \mathrm{~s}^{-1} \mathrm{~kg}^{-1}\right)$ in two experimental cases for each of the two stands, where $z$ is the depth (m).

\begin{tabular}{rcc}
\hline & P. densiflora & Q. myrsinaefolia \\
\hline$\underline{\text { Mixed stand }}$ & & \\
Case $A$ & $4.0 \times 10^{9}$ & $1.5 \times 10^{9}$ \\
Case B & $2.5 \times 10^{10} \exp (-3 \mathrm{z})$ & $1.5 \times 10^{9}$ \\
& \\
Pure stand & $1.3 \times 10^{10}$ & \\
Case A & & \\
Case B $B$ & $7.5 \times 10^{10} \exp (-3 \mathrm{z})$ & N/A \\
\hline
\end{tabular}


Table 3 Comparison of annual water flux components between observation and model.

Component / $P(\%)$

$$
T_{r P d} \quad T_{r Q m} \quad I_{c} \quad E_{f} \quad E T \quad \text { Reference }
$$

Mixed stand

$\begin{array}{rrrrrrl}\text { Observation } & 10 & 24 & 9 & 9 & 52 & \text { Iida, Tanaka, \& Sugita (2006) } \\ \text { Model } & 13 & 18 & 16 & 2 & 48 & \text { This study }\end{array}$

$\underline{\text { Pure stand }}$

$\begin{array}{lllllll}\text { Observation } & 28 & \text { N/A } & 17 & 7 & 53 & \text { Sugita (1987) }\end{array}$

Iida, Tanaka, \& Sugita (2006)

$\begin{array}{lllllll}\text { Model } & 43 & \text { N/A } & 18 & 3 & 64 & \text { This study }\end{array}$

P, precipitation; $T_{r P d}$, transpiration for Pinus densiflora; $T_{r Q m}$, transpiration for Quercus myrsinaefolia; $I_{c}$, interception; $E_{f}$, forest floor evaporation; $E T$, total evapotranspiration 
Figures

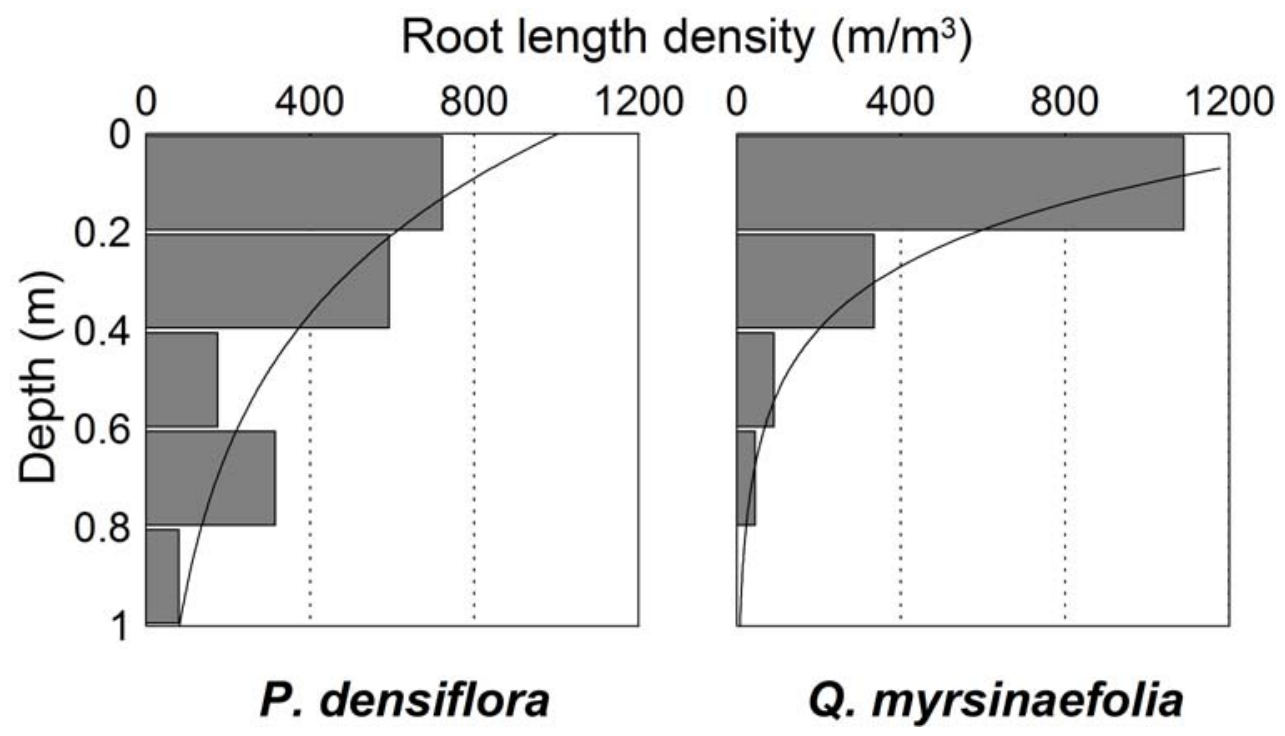

Figure 1 Depth-profile of root length density at the mixed stand (Yamanaka et al., 2005). Exponential functions from regression analysis were also shown. 


\section{a) Original isoRHEA}

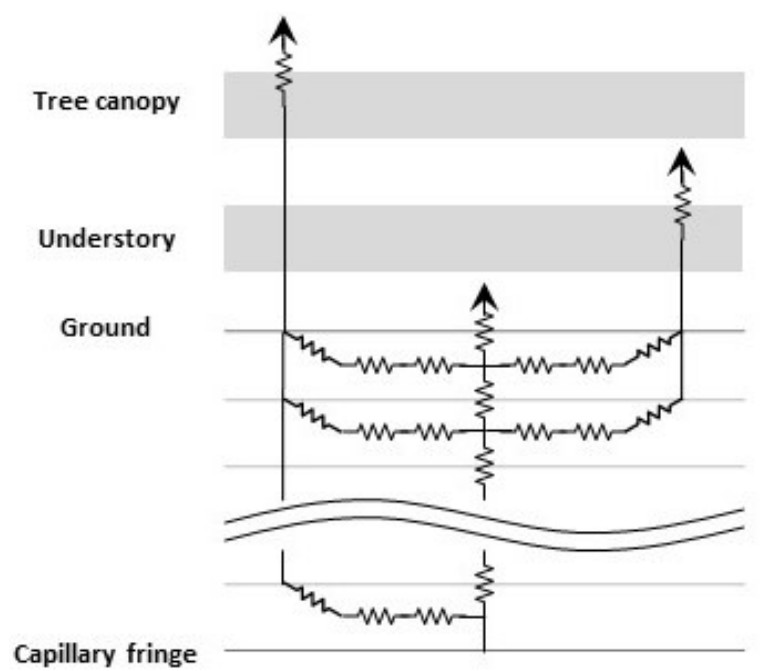

b) Modified isoRHEA

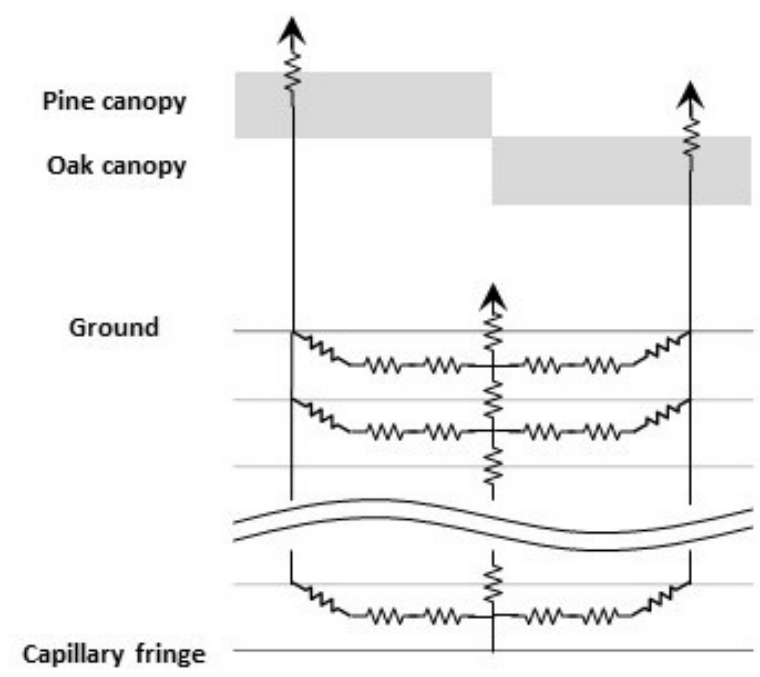

Figure 2 Schematic illustrations of original (for the pure stand) and modified (for the mixed stand) isoRHEA models. 


\section{a) Case $A$}

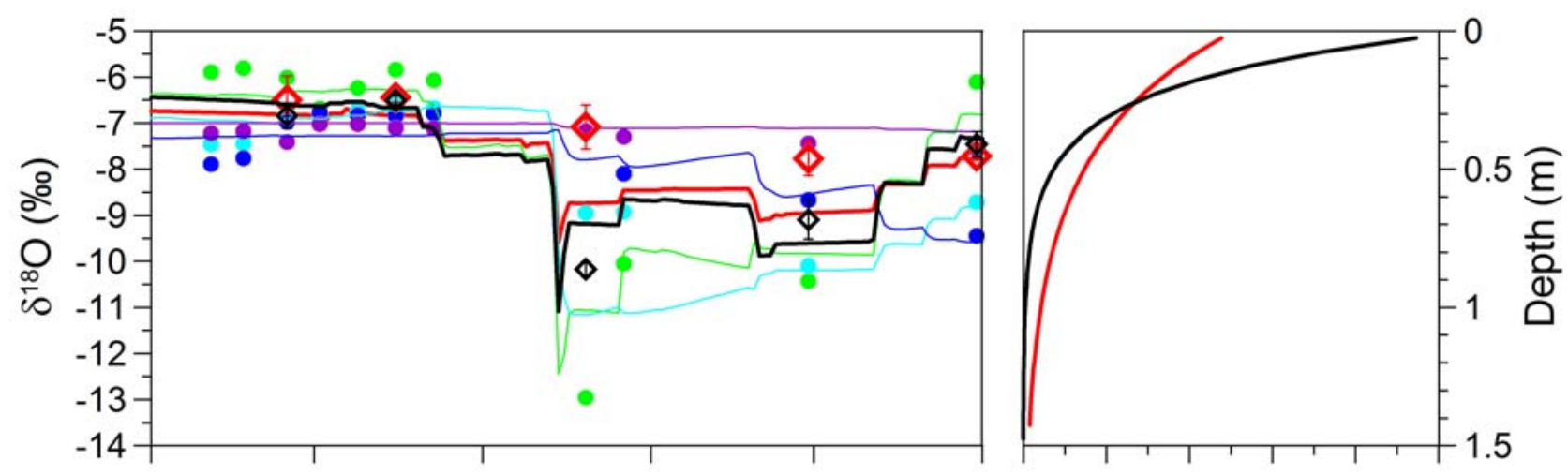

b) Case B
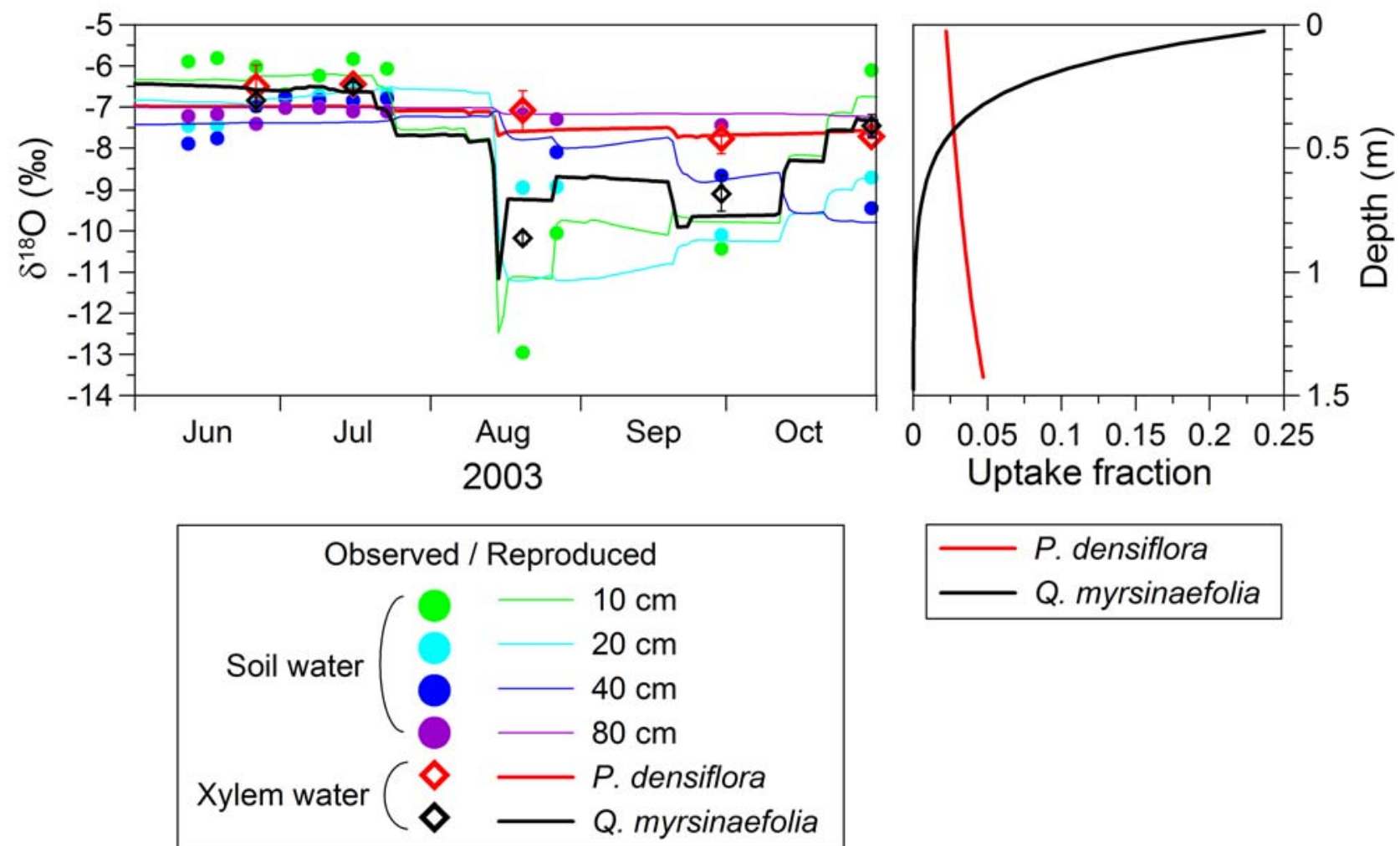

Figure 3 Results in the mixed stand on (left) temporal variation of observed and reproduced $\delta^{18} \mathrm{O}$ of soil/xylem waters and (right) reproduced depth-profile of uptake fraction per 5-cm depth intervals for (a) Case A and (b) Case B. 


\section{a) Case $A$}
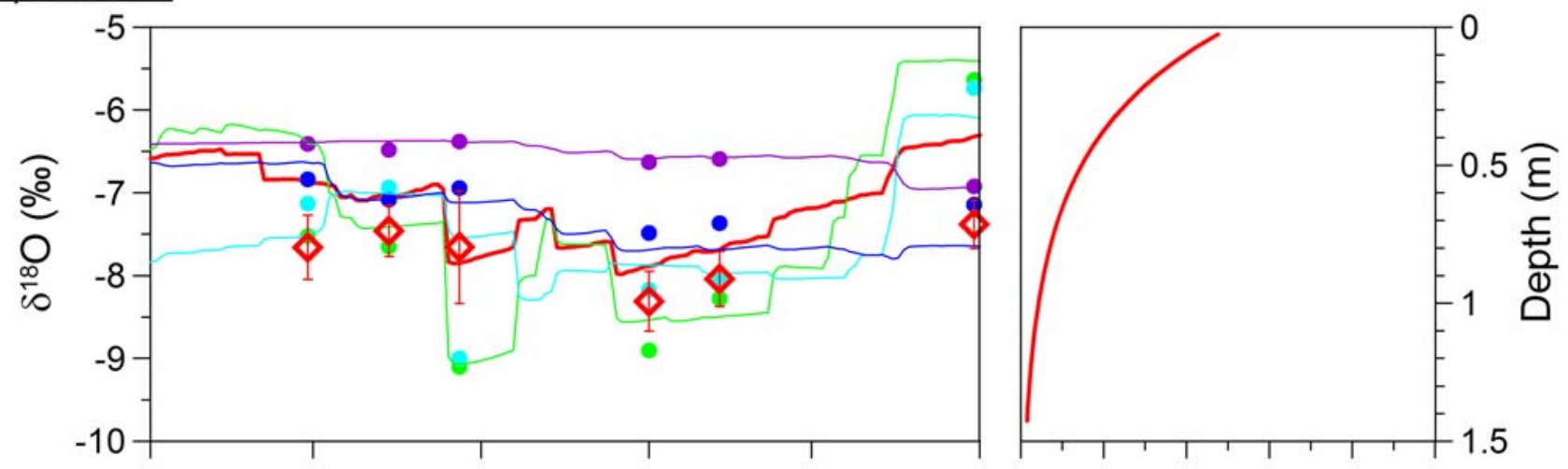

b) Case B
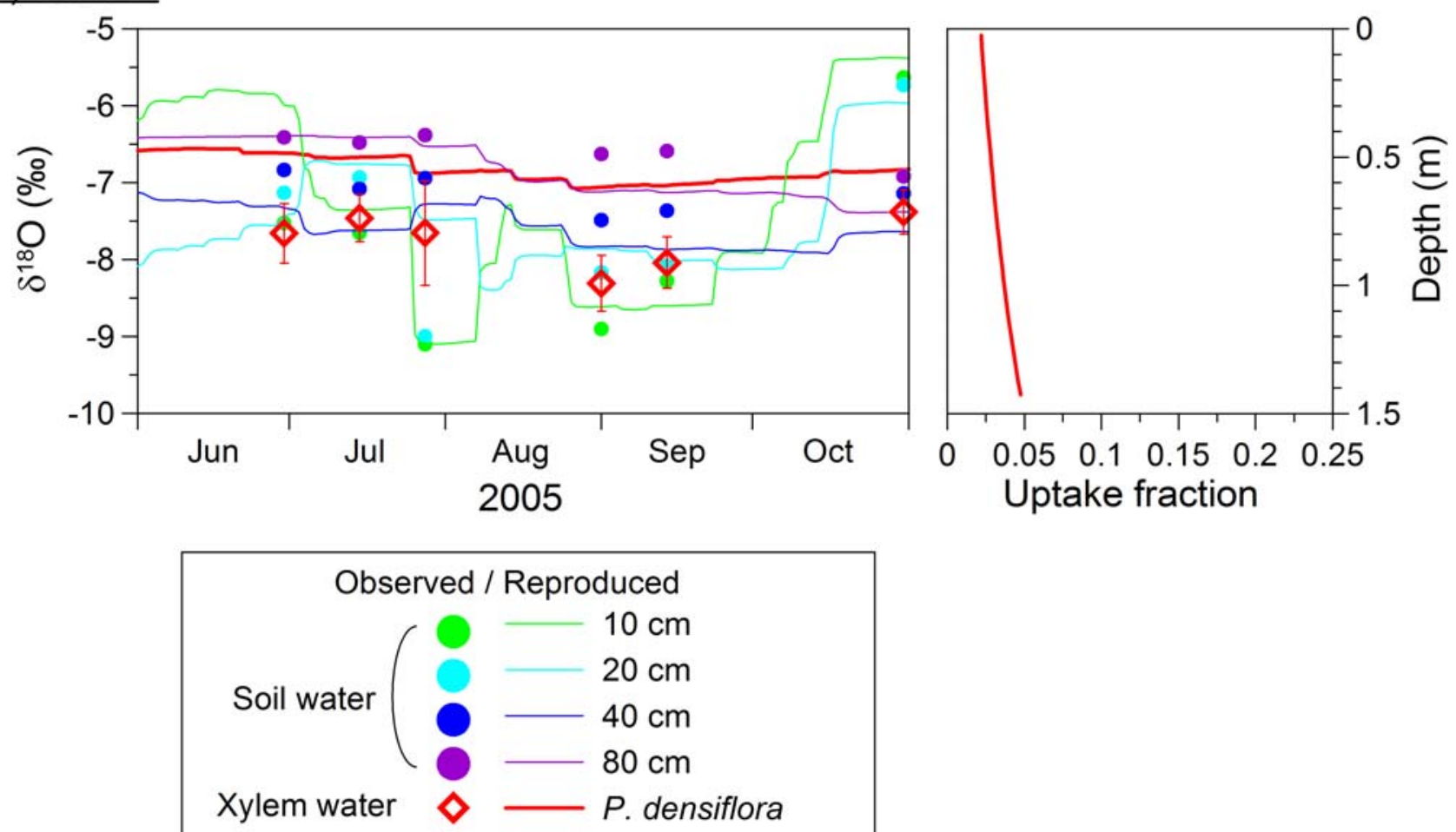

Figure 4 Same as Fig. 3 but in the pure stand. 


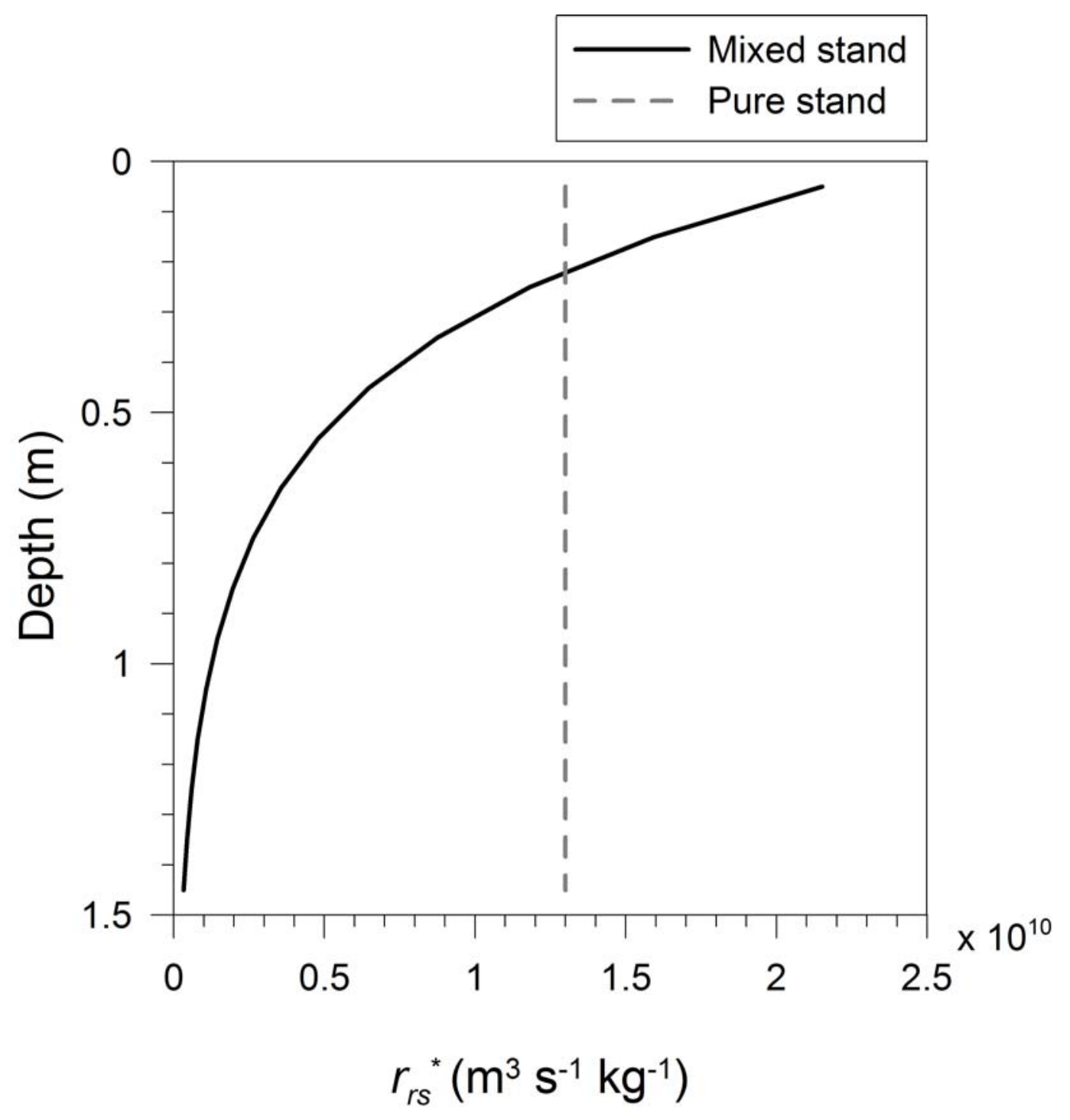

Figure 5 Vertical profiles of the root surface resistance per unit length of roots $\left(r_{r s}{ }^{*}\right)$ in the two study stands. 